CLINICAL STUDY

\title{
Associations between body mass, leptin, IGF-I and circulating adrenal androgens in children with obesity and premature adrenarche
}

\author{
Dagmar l'Allemand, Stefan Schmidt, Valentin Rousson ${ }^{1}$, Georg Brabant ${ }^{2}$, Theo Gasser ${ }^{1}$ and Annette Grüters \\ Children's Hospital, Charité Campus Virchow, Humboldt University, Berlin, Germany, ${ }^{1}$ Department of Biostatistics, University of Zurich, Switzerland \\ and ${ }^{2}$ Department of Medicine, University of Hannover, Germany \\ (Correspondence should be addressed to A Grüters-Kieslich, Charité Kinderklinik, Campus Virchow, Humboldt Universität, Augustenburger Platz 1, \\ D-13353 Berlin, Germany; Email: annette.grueters@charite.de)
}

\begin{abstract}
Objective: To explain why adrenal androgens rise with increasing adiposity during childhood, the role of body mass index (BMI), leptin and IGF-I was studied. We also tested whether these parameters contribute to inducing premature adrenarche (PA).

Design: In a cross-sectional study, 26 prepubertal obese children were compared with a group of 26 prepubertal children of normal weight, and 30 children under observation for PA were compared with 30 healthy children, matched for gender, bone age and BMI.

Methods: Relative contributions of BMI standard deviation scores (SDS) and height SDS, as well as unbound leptin and IGF-I, to the levels of androgens, dehydroepiandrosterone sulfate (DHEAS) and $\Delta 4$-androstenedione (AD) were investigated by means of stepwise regression models. Logarithms of all hormones were standardised for age using residuals of a simple regression analysis, labelled by the suffix 'res'.

Results: In the obese children, height SDS, IGF-I $\mathrm{I}_{\text {res }}$ DHEAS $_{\text {res }}$ (all $\left.P<0.05\right)$, $\operatorname{leptin}_{\text {res }}(P<0.01)$, and $\mathrm{AD}_{\text {res }}(P=0.07)$ were higher than in the controls, and covariates were correlated with each other

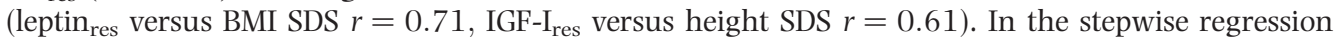
analysis of control and obese children, BMI SDS explained $26 \%$ and $\operatorname{leptin}_{\text {res }}$ explained $12 \%$ of the variability of DHEAS res, but this percentage remained at $26 \%$ when both variables were simultaneously introduced into the model. In contrast, IGF-I $\mathrm{I}_{\text {res }}$ and BMI SDS alone each accounted for $15 \%$ of the variability of $\mathrm{AD}$, and their joint influence accumulated to explain $28 \%$ of the variability of $\mathrm{AD}_{\text {res. }}$ In PA, neither BMI SDS nor leptin ${ }_{\text {res }}$ were correlated with the increased androgens.

Conclusion: Before the onset of gonadal activity in obese and control children, DHEAS levels, to some extent, are explained by BMI and leptin, while IGF-I in addition to BMI in part accounts for AD levels. Enhanced adrenal androgen secretion in children with PA, however, may be explained by parameters other than leptin or BMI.
\end{abstract}

European Journal of Endocrinology 146 537-543

\section{Introduction}

Adrenal androgens are increased in children with obesity $(1,2)$, and they have been made responsible for their accelerated growth before puberty (3), but the underlying regulatory mechanism of their stimulation remains unknown. Since fat cells produce leptin, it is reasonable to study whether leptin interferes with endocrine alterations observed in obesity. In humans, leptin deficiency accounts for hyperphagia, decreased sympathetic activity and hypogonadism $(4,5)$. Leptin seems to trigger pubertal development in primates, as before puberty it increases nightly to induce enhanced gonadotrophin-releasing hormone pulsatility and luteinizing hormone secretion (6). Thus leptin may represent the metabolic gate to initiate puberty (7). In humans, data to support a comparable function of leptin are scarce. It was deduced from cross-sectional studies that leptin levels may rise before the onset of puberty $(7-10)$, but this has been clearly documented in only one longitudinal study of boys (11).

In addition, the adrenal gland contributes to pubertal development and sex steroid secretion. Longitudinal studies have shown that, independent of age and genetic determination (12), the individual increase of body mass as such is a factor that markedly affects the rise of adrenal androgen secretion at the time of adrenarche. Leptin may represent one factor mediating 
in this event, since the ob receptor is expressed in adrenal tissue (13). Recent data indicate that leptin has a specific, dose-dependent role to promote the formation of adrenal androgens, stimulating 17,20-lyase activity of cytochrome P45017 (14). In addition leptin acts in concert with other growth-derived signals, such as growth hormone $(\mathrm{GH})$ and insulin-like growth factor-I (IGF-I) $(6,15)$, to regulate the onset of puberty in humans and primates. IGFs, in vitro, activate the expression of adrenal enzymes and increase the activity of the 17,20-lyase selectively, yielding a higher rate of $\Delta 4$-androstenedione (AD) formation (16).

Furthermore, dehydroepiandrosterone sulfate (DHEAS) and AD themselves are correlated with adiposity, as indicated in the following. First, fat cells can store and metabolise steroid hormones (17, 18). Second, insulin resistance, as is often observed in obesity (19), results in hyperinsulinism and enhanced activity of IGF-I, and has been shown to be associated with increased androgen levels in adolescent girl (20). However, these interrelationships may differ according to age or gender. In obese women, DHEAS levels are slightly increased and independent of insulin secretion, but positively correlated with IGF-I (21). In contrast, in adult men with obesity (22) and hyperinsulinaemia (23, 24) DHEA(S) is decreased. Levels of dehydroepiandrosterone or DHEAS are similarly reduced in women with severe obesity or type 2 diabetes $(25,26)$.

So far, it has not yet been shown in prepubertal children how leptin, IGF and adrenal androgens, as well as parameters of obesity are interrelated. The aim of the present study was to measure adrenal androgen levels in children of normal weight and with obesity, and to correlate them with leptin and anthropometric variables. A second aim was to analyse the influence of IGF-I on adrenal androgens in lean and obese children. Furthermore, additional investigations were carried out on a group of children with premature adrenarche (PA), to answer the question as to whether the elevation of adrenal androgens in this disorder is the consequence of obesity, or directly to a rise of leptin, or both.

\section{Patients and methods}

In this cross-sectional study, 52 healthy children were investigated in our outpatient department in the following groups. Obese group, 26 prepubertal children with obesity, defined by body mass index (BMI) standard deviation score (SDS) above 3 and control group, 26 children considered as normal weight controls, comprising 19 children with congenital hypothyroidism, detected by newborn thyrotrophin screening, and treated with thyroxine since the first 2 weeks of life, in whom normal growth and pubertal development have recently been described (27), and seven children with untreated familial tall stature, defined by a height above the 97 th percentile for age (28). Tall children may be included as controls, since growth is accelerated in obese children (3). In addition, 30 children with idiopathic PA or hirsutism with a history of PA were included for comparison, because of their precocious, increased secretion of adrenal androgens. This group included 13 children who had already entered puberty with breast or genital stage $\leq 2$. An adrenal enzyme defect had previously been excluded by an adrenocorticotrophin (ACTH) stimulation test (29). This group was compared with 30 healthy children as described above, and matched for gender, bone age and BMI to each PA subject.

The study was approved by the Ethics Committee of the Humboldt University Hospital, Campus Virchow, and informed consent was given by the parents. No more than $1 \mathrm{ml}$ serum was available from each child and therefore not all hormones could be determined in each patient. IGF-I was not determined in the PA group.

Height, weight and pubertal stages were assessed according to standard methods (28) (Table 1). To adjust for gender and age, height and BMI (weight in $\mathrm{kg}$ divided by the square of the height in $\mathrm{m}$ ) were given as SDS using the First Zurich Longitudinal Study (ZLS) as reference (28). Obesity was defined by a BMI SDS above 3, because this is the only limit that allows for the selection of markedly obese children.

Table 1 Clinical data given as medians and ranges (in parentheses).

\begin{tabular}{|c|c|c|c|c|}
\hline Group & Prepubertal obese & Prepubertal controls & $\mathbf{P A}^{1}$ & Matched controls for $\mathrm{PA}^{1}$ \\
\hline Total no. (girls) & $26(16)$ & $26(17)$ & $30(21)$ & $30(21)$ \\
\hline Chronological age & $8.5(2.9-13.1)$ & $8.0(2.7-11.4)$ & $9.1(5.0-17.1)$ & $9.3(5.1-15.0)$ \\
\hline Bone age & $10.0(4.0-13.8)$ & $8.5(4.3-11.5)$ & $10.5(5.0-18.0)$ & $10.0(5.0-15.0)$ \\
\hline $\mathrm{P}$ stage & 1 & 1 & $3^{* *}(2-6)$ & $1(1-5)$ \\
\hline B or G stage & 1 & 1 & $1(1-5)$ & $1(1-5)$ \\
\hline Height SDS & $2.5^{\star}(-2.3-4.1)$ & $0.4(-1.9-3.9)$ & $0.7(-2.1-5.2)$ & $1.1(-1.9-4.4)$ \\
\hline BMI SDS & $5.6^{\star \star \star}(3.1-9.5)^{\prime}$ & $0.5(-0.9-2.8)$ & $1.5(-2.9-8.1)$ & $1.8(-1.0-7.2)$ \\
\hline
\end{tabular}

${ }^{1} 13 / 30$ children with breast or genital stage $\geq 2$.

PA controls $=$ controls matched with PA for gender, BMl and bone age.

$\mathrm{P}, \mathrm{B}, \mathrm{G}=$ Tanner pubertal stages of public hair, breast and genitalia respectively.

${ }^{\star} P<0.05,{ }^{* \star} P<0.01,{ }^{* \star} P<0.001$, significant differences versus matched control group. 
Bone age was determined according to Greulich \& Pyle (30). There were no statistical differences between the obese children or the children with PA and their respective control groups regarding age, bone age, pubertal stage, as analysed by Mann-Whitney test, and sex distribution, as analysed by a chi-square test (Table 1). The only significant difference was found for the advanced pubic hair stage in the PA group, which is inherent to the diagnosis.

The following hormones were measured by direct specific radioimmunoassays with the inter-assay coefficients of variation (CV) as indicated, and slightly lower intra-assay CV values (data not shown): DHEAS (IBL/RSL, Hamburg, Germany, $\mathrm{CV}=9.2 \%$ at 1605 $\mathrm{ng} / \mathrm{ml}, n=25$ ), AD (DSL, Sinsheim, Germany, $\mathrm{CV}=$ $5.5 \%$ at $1.21 \mathrm{ng} / \mathrm{ml}, n=30$ ) and IGF-I (Mediagnost, Tuebingen, Germany, $\mathrm{CV}=7.2 \%$ at $114 \mathrm{ng} / \mathrm{ml}$, $n=14)$ and unbound leptin as published by Horn et al. (31), (CV $=8.3 \%$ at $110 \mathrm{pmol} / \mathrm{l}, n=6)$.

Age-dependent reference ranges for the methods used have been established in our laboratory (Table 2), with the exception of AD and leptin. For these methods, normative data of children younger than 3 and 8 years respectively were not available; however, all hormones were dependent on age. The hormones entered into the regression analysis were therefore standardised for age as described below. There was no significant sex difference in hormone levels, as assessed by the Mann-Whitney test. As a consequence, all hormones were calculated on boys and girls combined.

Table 2 Hormone levels in the study groups and reference ranges.

\begin{tabular}{|c|c|c|c|c|}
\hline & $\begin{array}{l}\text { Leptin } \\
(\mathrm{pmol} / \mathrm{l})\end{array}$ & $\begin{array}{c}\text { IGF-I } \\
(\mathrm{nmol} / \mathrm{l})\end{array}$ & $\begin{array}{l}\text { DHEAS } \\
(\mu \mathrm{mol} / \mathrm{l})\end{array}$ & $\begin{array}{c}\mathbf{A D} \\
(\mathrm{nmol} / \mathrm{l})\end{array}$ \\
\hline \multicolumn{5}{|c|}{ Prepubertal obese } \\
\hline No. & 26 & 16 & 23 & 22 \\
\hline Median & $192^{\star \star \star}$ & $26.4^{*}$ & $2.47^{*}$ & $\left.1.88^{*}\right)$ \\
\hline Range & $41-498$ & $11.1-55.4$ & $0.61-8.1$ & $0.17-12.6$ \\
\hline \multicolumn{5}{|c|}{ Prepubertal controls } \\
\hline No. & 26 & 16 & 14 & 13 \\
\hline Median & 36.5 & 17.7 & 0.48 & 0.84 \\
\hline Range & $12-392$ & $7.9-38.3$ & $0.21-4.54$ & $0.17-3.98$ \\
\hline \multicolumn{5}{|c|}{ Normal reference values } \\
\hline Age (years) & $8-10$ & $2-10$ & $2-10$ & $3-10$ \\
\hline Median & 19.5 & 17.4 & 0.61 & 0.98 \\
\hline Range & $10-92$ & $5.1-43.2$ & $0.21-3.4$ & $0.17-2.6$ \\
\hline \multicolumn{5}{|l|}{ PA patients } \\
\hline No. & 30 & n.d. & 29 & 16 \\
\hline Median & 48 & & $6.1 \varepsilon$ & $4.05^{\#}$ \\
\hline Range & $12-733$ & & $0.59-14.6$ & $1.05-14.7$ \\
\hline \multicolumn{5}{|l|}{ PA controls } \\
\hline No. & 30 & n.d. & 29 & 19 \\
\hline Median & 54 & & 3.08 & 2.06 \\
\hline Range & $12-431$ & & $0.29-9.5$ & $0.17-6.35$ \\
\hline
\end{tabular}

${ }^{\star} P<0.05,{ }^{* \star} P<0.01,{ }^{* \star \star} P<0.001$, significant differences versus controls (Student's $t$-test); ( $\left.{ }^{*}\right)$ trend, $P=0.07$ versus controls; ${ }^{\#} P<0.05$ difference from controls only significant by non-parametric Mann-Whitney test. n.d. $=$ not done.

\section{Statistics}

Because most of the variables showed a skew distribution, data were summarised by medians and ranges. Logarithms of hormone variables, i.e. leptin, IGF-I, DHEAS and AD, showed an approximately normal distribution. Because all these variables were clearly age dependent, we established age-standardised values. To do so, we calculated a least squares fit with age as explanatory variable and the logarithm of the hormone as the response. This regression was made using all the children except those of the PA group because, in the latter, the relationship between age and hormonal parameters is atypical. Age-standardised values were then defined as the residuals with respect to this fit (this was done also for the PA group). We refer to them as leptin $_{\text {res }}$, IGF-I I $_{\text {res }}, D_{\text {DEAS }}$ res and $\mathrm{AD}_{\text {res. }}$. Note that this standardisation technique is equivalent to considering age as a covariate.

In order to compare the obese and the control group, as well as the PA and the PA control group with respect to leptin $_{\text {res }}, \mathrm{IGF}_{\mathrm{r}}, \mathrm{DHEAS}_{\text {res }}, \mathrm{AD}_{\text {res }}$, height SDS and BMI SDS, we used two sample $t$-tests.

In order to investigate the relative contribution of anthropometric variables (BMI SDS and height SDS) and hormonal variables $\left(\right.$ leptin $_{\text {res }}$ and IGF-I $\mathrm{I}_{\text {res }}$ ) to the levels of $\mathrm{DHEAS}_{\text {res }}$ and $\mathrm{AD}_{\text {res}}$, we considered stepwise regression models with two explanatory variables. The relationship between an 'explanatory' variable

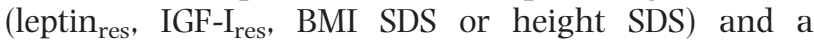
response $\left(\mathrm{DHEAS}_{\text {res }}\right.$ or $\left.\mathrm{AD}_{\text {res }}\right)$ was characterised by the Pearson correlation coefficient $\left(\mathrm{r}_{\mathrm{Pea}}\right)$ or equivalently by its square $R^{2} \times 100$, which represents the percentage of variability of the response indicated by the explanatory variable. We also investigated the relationship between two explanatory variables in this way. In the regression models with two explanatory variables, we used $\mathrm{F}$ tests to assess the joint influence, and partial F tests to assess the contribution of each explanatory variable. All regression models with one or two explanatory variables were calculated using both the obese and the control groups. We also calculated such models in the PA group. However, hormonal variables scattered unevenly because 13 children had already entered puberty with breast (B) or genital (G) development; hence, regression analysis was additionally tested in the separate 'prepubertal' PA group (B1, G1, pubic hair stage $\geq 2$ ).

Throughout the analyses, $P$ values below 0.05 were considered significant.

\section{Results}

\section{Anthropometric and hormonal data of prepubertal obese and control children}

In children with obesity, BMI SDS was increased by definition and height SDS was also significantly elevated 
(Table 1). The anthropometric data were reflected by the pattern of leptin and IGF-I (Table 2): leptin $_{\text {res }}$ and IGF-I $\mathrm{I}_{\text {res }}$ were significantly higher in the obese group compared with controls. DHEAS ${ }_{\text {res }}$ (Table 2) was significantly higher in the obese children than in the controls. There was a trend for higher $\mathrm{AD}_{\text {res }}$ in the obese group $(P=0.07)$.

\section{Regression analyses to explain DHEAS and AD in the combined group of obese and control children}

Before entering explanatory variables into the regression model to recognise their relative contribution to explain the variability of adrenal androgens, we tested the influence of age. As mentioned above, all hormones were clearly age dependent: in the combined prepubertal group (obese and controls), age accounted for about half of the variability of the logarithms of IGF-I, DHEAS and AD $\left(\% \mathrm{R}^{2}\right.$ (square of Pearson regression coefficient $\times 100)=48,55$ and 55 respectively, with $P<0.0001)$, and for $16 \%$ of leptin $(P<$ 0.0001). We also tested the potential relationships between the covariates themselves. As shown by others, we found strong correlations between some covariates: leptin res $_{\text {was }}$ correlated with BMI SDS ( $r=0.71, P<0.001)$, and IGF-I $\mathrm{I}_{\text {res }}$ with height SDS $(r=0.61, \quad P<0.001)$. In the regression model, leptin $_{\text {res }}$ was significantly correlated with DHEAS explaining about $12 \%$ of the androgen's variability (Table 3); the introduction of BMI SDS into the model significantly improved the explanation of the DHEAS response to $26 \%$, but neither the introduction of height SDS nor of IGF-I $_{\text {res }}$ (not shown) in addition to leptin changed the explanation of DHEAS variance. BMI SDS alone explained about $26 \%$ of the variability of DHEAS $_{\text {res, }}$ and this relationship was not changed if leptin $_{\text {res }}$ was introduced into the model. Hence, we concluded that leptin, at least in part, could be a mediating signal of BMI with respect to its contribution in explaining DHEAS levels. The model with BMI SDS was also not improved by the addition of $\mathrm{IGF}_{\mathrm{r}} \mathrm{I}_{\mathrm{res}}$ or height SDS. While IGF-I $\mathrm{I}_{\text {res }}$ was not correlated with DHEAS $_{\text {res, }}$ it was an important variable to explain $\mathrm{AD}_{\text {res }}$, accounting for about $15 \%$ of its variance (Table 3). BMI SDS significantly added about 13\% to the explanatory model, yielding $28 \%$ together with IGF-I $_{\text {res. }}$. Neither leptin ${ }_{\text {res }}$ nor height SDS, in any combination, were found to make significant contributions to improving the association between IGF- $\mathrm{I}_{\text {res }}$ and $\mathrm{DHEAS}_{\text {res }}$ or $\mathrm{AD}_{\text {res. }}$.

\section{PA group}

To examine the relation between leptin or body mass and increased adrenal androgen secretion in children with PA (Table 4), we adopted two approaches. First, hormonal data of the patients with PA were compared with controls matched for gender, bone age and BMI, to minimise the influence of these covariates. Second, the interaction between adrenal androgens, leptin and several auxological parameters was tested by multiple regression analysis in the PA group only.

First, BMI in the PA group (Table 1) was increased, on average, as can be deduced from the fact that the median BMI SDS was 1.5 times higher than the average of the ZLS references. Then, as the PA group was compared with the matched control group, BMI SDS did not differ significantly and leptin was also similar in both groups, while DHEAS and $\mathrm{AD}$ were still elevated in the entire PA group (Table 2), or in 'prepubertal' PA children (data not shown; $P<0.01$ and $P<0.05$ respectively). Therefore, leptin had no specific effect, beyond mediating obesity, to account for increased adrenal androgen levels in PA subjects.

This observation was further tested by multiple regression analysis, as explained in the section on Patients and methods. Despite the fact that in the PA group the covariates leptin and BMI SDS were significantly correlated $(r=0.71, \quad P<0.001)$, neither

Table 3 Regression models in prepubertal children: combined group of control and obese children.

\begin{tabular}{|c|c|c|c|c|c|c|c|c|c|c|c|c|c|}
\hline \multirow[b]{2}{*}{ Response } & \multirow{2}{*}{$\begin{array}{c}\text { 1st explanatory } \\
\text { variable }\left(x_{1}\right)\end{array}$} & \multicolumn{3}{|c|}{ Model with $x_{1}$} & \multirow{2}{*}{$\begin{array}{c}\text { 2nd explanatory } \\
\text { variable }\left(x_{2}\right)\end{array}$} & \multicolumn{3}{|c|}{ Model with $x_{2}$} & \multicolumn{4}{|c|}{ Model with $x_{1}$ and $x_{2}$} & \multirow[b]{2}{*}{ No. } \\
\hline & & $\mathrm{r}_{\mathrm{Pea}}$ & $\% \mathrm{R}^{2}$ & $P$ & & $r_{\text {Pea }}$ & $\% R^{2}$ & $P$ & $\% \mathrm{R}^{2}$ & $P$ & $P_{\mathrm{x} 1}$ & $P_{\mathrm{x} 2}$ & \\
\hline DHEAS $_{\text {res }}$ & Leptin $_{\text {res }}$ & 0.35 & 12 & * & BMI SDS & 0.51 & 26 & $\star \star \star$ & 26 & ** & n.s. & * & 37 \\
\hline DHEAS res & $I G F-I_{\text {res }}$ & 0.20 & 4 & n.s. & BMI SDS & 0.47 & 22 & * & 23 & * & n.s. & * & 27 \\
\hline DHEAS res & BMI SDS & 0.51 & 26 & 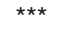 & Height SDS & 0.17 & 3 & n.s. & 27 & $\star \star$ & $\star \star$ & n.s. & 37 \\
\hline$A D_{\text {res }}$ & Leptin $_{\text {res }}$ & 0.25 & 6 & n.s. & BMI SDS & 0.28 & 8 & n.s. & 9 & n.s. & n.s. & n.s. & 35 \\
\hline$A D_{\text {res }}$ & IGF-I res & 0.39 & 15 & * & BMI SDS & 0.39 & 15 & * & 28 & * & * & n.s. & 27 \\
\hline$A D_{\text {res }}$ & BMI SDS & 0.28 & 8 & n.s. & Height SDS & 0.20 & 4 & n.s. & 11 & n.s. & n.s. & n.s. & 35 \\
\hline
\end{tabular}

Response $=$ dependent variable considered: $x_{1}, x_{2}=1$ st and 2 nd explanatory or independent variables brought into the regression model; $r_{\text {Pea }}=$ Pearsons correlation coefficient; $\% R^{2}=$ square of $r_{P e a} \times 100$, indicating the percent of variation of the response being explained by the 1 st or the 2 nd explanatory variable, both together; $P=$ associated significance: ${ }^{\star} P<0.05,{ }^{\star \star} P<0.01,{ }^{\star \star *} P<0.001$, significant relationship between explanatory variable and response in bold type. n.s. = not significant.

$P_{\mathrm{x} 1}=$ significance of introducing the 1 st explanatory variable into the model, when the 2nd one is already in. $P_{\mathrm{x} 2}=$ significance of introducing the 2 nd explanatory variable into model, when the 1 st one is already in.

No. = sample size available for the analysis of correlation. 
Table 4 Regression models in prepubertal children of the PA group.

\begin{tabular}{|c|c|c|c|c|c|c|c|c|c|c|c|c|c|}
\hline \multirow[b]{2}{*}{ Response } & \multirow{2}{*}{$\begin{array}{l}\text { 1st explanatory } \\
\text { variable }\left(x_{1}\right)\end{array}$} & \multicolumn{3}{|c|}{ Model with $x_{1}$} & \multirow{2}{*}{$\begin{array}{l}\text { 2nd explanatory } \\
\text { variable }\left(x_{2}\right)\end{array}$} & \multicolumn{3}{|c|}{ Model with $x_{2}$} & \multicolumn{4}{|c|}{ Model with $x_{1}$ and $x_{2}$} & \multirow[b]{2}{*}{ No. } \\
\hline & & $\mathrm{r}_{\mathrm{Pea}}$ & $\% \mathrm{R}^{2}$ & $P$ & & $\mathrm{r}_{\text {Pea }}$ & $\% R^{2}$ & $P$ & $\% \mathrm{R}^{2}$ & $P$ & $P_{\mathrm{x} 1}$ & $\overline{P_{\mathrm{x} 2}}$ & \\
\hline DHEAS $_{\text {res }}$ & Leptin $_{\text {res }}$ & 0.17 & 6 & n.s. & BMI SDS & 0.14 & 2 & n.s. & 6 & n.s. & n.s. & n.s. & 17 \\
\hline DHEAS $_{\text {res }}$ & BMI SDS & 0.14 & 2 & n.s. & Height SDS & 0.33 & 11 & n.s. & 11 & n.s. & n.s. & n.s. & 17 \\
\hline
\end{tabular}

See Table 3 for explanation of terms.

The sample size in this group was too small to perform the regression analyses with AD.

leptin $_{\text {res }}$ nor BMI SDS alone or in combination were correlated with DHEAS $S_{\text {res }}$ or $\mathrm{AD}_{\text {res }}$, no matter whether testing was done for the entire PA group (data not shown) or the 'prepubertal' PA children (Table 4). Height SDS was significantly correlated with DHEAS res $_{\text {r }}$ in the entire PA group ( $\mathrm{r}_{\mathrm{Pea}}=0.42, P<0.05$ ), apparently as a consequence of the effects of DHEA/DHEAS on growth promotion.

\section{Discussion}

The present data for the first time support the hypothesis that leptin and IGF-I may act as mediators to signal changes in body composition or size and to increase adrenal androgen secretion. Our study provides data for prepubertal girls and boys over a broad range of body weight, to demonstrate that adrenal androgens increase with adiposity, as assessed by BMI SDS. Previous studies merely included selected cohorts of girls with a specific range of age and weight $(1,32)$, or of boys (2). The present study provides a methodological advantage in so far as it is the first to measure free leptin in children, which is more accurately correlated with fat tissue than total leptin (33). Our main results may be summarised as follows. (a) In prepubertal children with obesity, DHEAS and $\mathrm{AD}$ as well as leptin and IGF-I are elevated. Before puberty, BMI SDS and leptin together explain $26 \%$ of the DHEAS response in obese and control children after correction for age. Leptin, in its own right, has a weak influence on DHEAS $(12 \%)$, but leptin is not an independent factor in addition to BMI to explain DHEAS, while BMI SDS alone explains $26 \%$. The variability of the response of $\mathrm{AD}$ is essentially (28\%) explained by IGF-I in concert with BMI, but also by IGF-I (15\%) and BMI SDS (15\%) alone. (b) Children with PA have an increased BMI on average, but BMI is not significantly correlated with adrenal androgens in this group. After control for age and adiposity, leptin has no significance in explaining the increased adrenal androgen levels in PA subjects.

Before the pubertal onset of gonadal activity, the levels of DHEAS seem to be mainly related to leptin and $\mathrm{BMI}$, whereas the levels of $\mathrm{AD}$ are more closely linked to IGF-I and BMI. BMI, however, does not precisely represent fat mass, but also mirrors height, at least in lean children. Since IGF-I was significantly correlated with height, our results may suggest that the effects of fat mass are mediated by leptin, and those of height or lean mass by IGF-I. In fact, more studies will be necessary to establish the contribution of each compartment of body composition to affect adrenal androgen secretion. The sequence of these associations cannot be extrapolated from the present cross-sectional study but from other publications as follows. From in vitro experiments, it can be deduced that leptin $(13,14)$ and IGF-I $(16,34)$ each directly account for changes in adrenal enzyme activity or expression. Longitudinal studies have revealed in vivo that BMI SDS changes precede adrenarche (12), and that leptin (11) and IGF-I (6) increase before steroid hormones are secreted. Leptin and IGF-I both increase before puberty and might provide the brain with information on body composition and size to start pituitary, adrenal and gonadal maturation $(6,12)$. The involvement of IGF-I in the regulation of adrenal androgens is confirmed by a clinical study on girls with Turner's syndrome, which showed an increased stimulation of adrenal androgens in parallel with a rise of IGF-I levels after the initiation of GH therapy (35).

In children with PA, neither BMI nor leptin alone explain the precocious adrenal maturation. Nevertheless, the sample size of the present study may be too limited to reveal weak associations. As a matter of fact, there is no reason why obesity or BMI should not have an additional stimulating effect on adrenal androgen formation in children with PA, as demonstrated in healthy children. Altogether, we suggest that, in PA, additional factors are involved in the regulation of androgen secretion, e.g. mild enzyme defects, which might have been missed by routine ACTH testing in this study, or hyperinsulinism, as discussed below.

The positive correlation of adiposity, to the extent indicated by BMI, to androgens, observed in prepubertal children, contrasts with the regulation observed in adults. As discussed above, DHEAS levels, in relation to enhanced insulin secretion, may even be reduced as a result of increased metabolic turnover of this hormone (22-26). In fact, there are yet other factors in addition to IGF-I or leptin, which increase with body size or obesity and stimulate adrenal steroids, but their investigation could not be carried out in this study. Two candidate hormones have been shown to be associated with increased androgen levels in adolescent girls: corticotrophin-releasing hormone, which is 
activated in obesity and has recently been suggested to increase adrenal androgen secretion directly (36), and hyperinsulinism due to insulin resistance $(20,37)$. In prepubertal children, however, no correlation between insulin and DHEAS could be found (38). Puberty may lead to different, positive relationships of leptin to androgens, as shown recently (39). However, published data are contradictory: according to another study in adult women with polycystic ovary syndrome, leptin does not affect circulating sex hormones or insulin levels independently of BMI (40).

Nonetheless, the secretion of gonadal steroids in response to the pubertal increase of gonadotrophins is assumed to have a much stronger effect on circulating androgen levels, and may mask secretion and regulation of adrenal androgens (41). For that reason, a pubertal group was not included in the present study.

Moreover, as in PA, the leptin-BMI SDS-androgen interaction is complicated by testosterone itself, suppressing leptin secretion from adipocytes (42). Also, very high levels of leptin (100-1000 ng/ml) directly decrease adrenal steroid formation (13) by inhibiting the expression of the $17 \alpha-\mathrm{mRNA}$ in vitro. Such high leptin levels, as encountered in extremely obese adults, would outweigh the stimulation of androgen formation at low leptin levels. Therefore, the switch from a stimulated prepubertal to a different, 'adult' type of androgen regulation by leptin may be caused by higher doses of this peptide.

Further research on this issue is required, all the more since several other studies call attention to the consequences of an adrenal androgen increase in prepubertal and pubertal girls, affecting ovarian function in later life and representing a risk factor for ovarian hyperandrogenism $(43,44)$.

The causal relationship between prepubertal growthrelated signals and steroid secretion cannot be assessed by a cross-sectional study. However, when combining the present results with recent longitudinal studies on the onset of adrenal and gonadal maturation, it turns out that leptin and IGF-I signalling body mass are significant regulators of steroid secretion before the onset of puberty. This has also to be born in mind when $\mathrm{GH}$ is administered in non-classical indications, since one of the potential effects of IGF-I could be to induce adrenal androgen secretion.

\section{Acknowledgements}

Our grateful acknowledgements go to Bettina Tippel, Bernd Berger and Gabi Sahm of the paediatric endocrine laboratory for their assistance in collecting the data, and to the nursing staff of the endocrine outpatient department for their care of the patients. Parts of this work were supported by a grant from the Deutsche Forschungsgemeinschaft DFG AL332/2-2.

\section{References}

1 Genazzani AR, Pintor C \& Corda R. Plasma levels of gonadotropins, prolactin, thyroxine, and adrenal and gonadal steroids in obese prepubertal girls. Journal of Clinical Endocrinology and Metabolism 1978 47 974-979.

2 Pintor C, Loche S, Faedda A, Fanni V, Nurchi AM \& Corda R. Adrenal androgens in obese boys before and after weight loss. Hormones and Metabolic Research 198416 544-548.

3 De Simone M, Farello G, Palumbo M, Gentile T, Ciuffreda M, Olioso P et al. Growth charts, growth velocity and bone development in childhood obesity. International Journal of Obesity and Related Metabolic Disorders 199519 851-857.

4 Farooqi IS, Jebb SA, Langmack G, Lawrence E, Cheetham $\mathrm{CH}$, Prentice AM et al. Effects of recombinant leptin therapy in a child with congenital leptin deficiency. New England Journal of Medicine $1999341879-884$.

5 Ozata M, Ozdemir IC \& Licinio J. Human leptin deficiency caused by a missense mutation: multiple endocrine defects, decreased sympathetic tone, and immune system dysfunction indicate new targets for leptin action, greater central than peripheral resistance to the effects of leptin, and spontaneous correction of leptin-mediated defects. Journal of Clinical Endocrinology and Metabolism 199984 3686-3695.

6 Suter KJ, Pohl CR \& Wilson ME. Circulating concentrations of nocturnal leptin, growth hormone, and insulin-like growth factor-I increase before the onset of puberty in agonadal male monkeys: potential signals for the initiation of puberty. Journal of Clinical Endocrinology and Metabolism 200085 808-814.

7 Quinton ND, Smith RF, Clayton PE, Gill MS, Shalet S, Justice SK et al. Leptin binding activity changes with age: the link between leptin and puberty. Journal of Clinical Endocrinology and Metabolism $1999842336-2341$.

8 Matkovic V, Ilich JZ, Skugor M, Badenhop NE, Goel P, Clairmont A et al. Leptin is inversely related to age at menarche in human females. Journal of Clinical Endocrinology and Metabolism 1997 $823239-3245$.

9 Blum W, Englaro P, Hanitsch S, Juul A, Hertel N, Müller J et al. Plasma leptin levels in healthy children and adolescents: dependence on body mass index, body fat mass, gender, pubertal stage and testosterone. Journal of Clinical Endocrinology and Metabolism 199782 2904-2910.

10 Roemmich JN, Clark PA, Berr SS, Mai V, Mantzoros CS, Flier JS et al. Gender differences in leptin levels during puberty are related to the subcutaneous fat depot and sex steroids. American Journal of Physiology 1998275 E543-E551.

11 Mantzoros CS, Flier JS \& Rogol AD. A longitudinal assessment of hormonal and physical alterations during normal puberty in boys. V. Rising leptin levels may signal the onset of puberty. Journal of Clinical Endocrinology and Metabolism $1997 \mathbf{8 2}$ 1066-1070.

12 Remer T \& Manz F. Role of nutritional status in the regulation of adrenarche. Journal of Clinical Endocrinology and Metabolism 1999 84 3936-3944.

13 Glasow A, Haidan A, Hilbers U, Breidert M, Gillespie J, Scherbaum WA et al. Expression of $\mathrm{Ob}$ receptor in normal human adrenals: differential regulation of adrenocortical and adrenomedullary function by leptin. Journal of Clinical Endocrinology and Metabolism $1998834459-4466$.

14 Biason-Lauber A, Zachmann M \& Schoenle EJ. Effect of leptin on CYP17 enzymatic activities in human adrenal cells: new insight in the onset of adrenarche. Endocrinology 2000141 1446-1454.

15 Bourguignon JP, Gerard A, Alvarez Gonzalez ML, Fawe L \& Franchimont P. Effects of changes in nutritional conditions on timing of puberty: clinical evidence from adopted children and experimental studies in the male rat. Hormone Research 1992 38 (Suppl 1) 97-105.

16 l'Allemand D, Penhoat A, Lebrethon MC, Ardevol R, Baehr V, Oelkers W et al. Insulin-like growth factors enhance steroidogenic enzyme and corticotropin receptor messenger ribonucleic acid 
levels and corticotropin steroidogenic responsiveness in cultured human adrenocortical cells. Journal of Clinical Endocrinology and Metabolism $1996 \mathbf{8 1} 3892-3897$.

17 Deslypere JP, Verdonck L \& Vermeulen A. Fat tissue: a steroid reservoir and site of steroid metabolism. Journal of Clinical Endocrinology and Metabolism 198561 564-570.

18 Martel C, Melner MH, Gagne D, Simard J \& Labrie F. Widespread tissue distribution of steroid sulfatase, 3 beta-hydroxysteroid dehydrogenase/delta 5-delta 4 isomerase (3 beta-HSD), 17-beta-HSD $5 \alpha$-reductase and aromatase activities in the rhesus monkey. Molecular and Cellular Endocrinology 1994 104 103-111.

19 Zannolli R, Rebeggiani A, Chiarelli F \& Morgese G. Hyperinsulinism as a marker in obese children. American Journal of Diseases of Childhood $1993147837-841$.

20 Ibanez L, Potau N, Zampolli M, Rique S, Saenger P \& Carrascosa A. Hyperinsulinemia and decreased insulin-like growth factorbinding protein-1 are common features in prepubertal and pubertal girls with a history of premature pubarche. Journal of Clinical Endocrinology and Metabolism 199782 2283-2288.

21 Maccario M, Mazza E, Ramunni J, Oleandri SE, Savio P, Grottoli S et al. Relationships between dehydroepiandrosterone-sulphate and anthropometric, metabolic and hormonal variables in a large cohort of obese women. Clinical Endocrinology $1999 \mathbf{5 0}$ 595-600

22 Tchernof A, Despres JP, Belanger A, Dupont A, Prud'homme D, Moorjani S et al. Reduced testosterone and adrenal C19 steroid levels in obese men. Metabolism 199544 513-519.

23 Nestler JE, Usiskin KS, Barlascini CO, Welty DF, Clore JN \& Blackard WG. Suppression of serum dehydroepiandrosterone sulfate levels by insulin: an evaluation of possible mechanisms. Journal of Clinical Endocrinology and Metabolism 198969 1040-1046.

24 Pasquali R, Casimirri F, Cantobelli S, Melchionda N, Morselli Labate AM, Fabbri R et al. Effect of obesity and body fat distribution on sex hormones and insulin in men. Metabolism 1991 40 101-104.

25 Yamaguchi Y, Tanaka S, Yamakawa T, Kimura M, Ukawa K, Yamada Y et al. Reduced serum dehydroepiandrosterone levels in diabetic patients with hyperinsulinaemia. Clinical Endocrinology $199849377-383$.

26 De Pergola G, Giagulli VA, Garruti G, Cospite MR, Giorgino F, Cignarelli $\mathrm{M}$ et al. Low dehydroepiandrosterone circulating levels in premenopausal obese women with very high body mass index. Metabolism 199140 187-190.

27 Grüters A, Liesenkötter KP, Zapico M, Jenner A, Dütting C, Pfeiffer E et al. Results of the screening program for congenital hypothyroidism in Berlin. 1978-1995. Experimental and Clinical Endocrinology and Diabetes 1997105 (Suppl 4) 28-31.

28 Prader A, Largo R, Molinari L \& Issler C. Physical growth of Swiss children from birth to 20 years of age. Helvetica Paediatrica Acta 1989 (Suppl 52) 1-125.

29 Westphal S, l'Allemand D, Peter M, Zachmann M \& Grüters A. Longitudinal survey of premature adrenarche: the role of mild 3 $\beta$-hydroxysteroid-dehydrogenase-deficiency. Hormone Research 19954446 [Abstract].

30 Greulich W \& Pyle S. Radiographic Atlas of the Development of the Hand and Wrist. Stanford, CA, USA: Stanford University Press, 1959.

31 Horn R, Geldszus R, Potter E, von zur Mühlen MA \& Brabant G. Radioimmunoassay for the detection of leptin in human serum. Experimental and Clinical Endocrinology and Diabetes $1996 \mathbf{1 0 4}$ 454-458.
32 Wabitsch M, Blum W, Muche R, Heinze E, Haug C, Mayer H et al. Insulin-like growth factors and their binding proteins before and after weight loss and their associations with hormonal and metabolic parameters in obese adolescent girls. International Journal of Obesity and Related Metabolic Disorders 199620 1073-1080.

33 Brabant G, Horn R, von zur Mühlen MA, Mayr B, Wurster U, Heidenreich $\mathrm{F}$ et al. Free and protein bound leptin are distinct and independently controlled factors in energy regulation. Diabetologia $2000 \mathbf{4 3}$ 438-442.

34 Kristiansen SB, Endoh A, Casson PR, Buster JE \& Hornsby PJ. Induction of steroidogenic enzyme genes by insulin and IGF-I in cultured adult human adrenocortical cells. Steroids $1997 \mathbf{6 2}$ 258-265.

35 Balducci R, Toscano V, Larizza D, Mangiantini A, Galasso C, Municchi $\mathrm{G}$ et al. Effects of long-term growth hormone therapy on adrenal steroidogenesis in Turner syndrome. Hormone Research $199849210-215$.

36 Ibanez L, Potau N, Marcos MV \& de Zegher F. Corticotropin-releasing hormone: a potent androgen secretagogue in girls with hyperandrogenism after precocious pubarche. Journal of Clinical Endocrinology and Metabolism $1999 \mathbf{8 4} 4602-4606$.

37 Oppenheimer E, Linder B \& DiMartino-Nardi J. Decreased insulin sensitivity in prepubertal girls with premature adrenarche and acanthosis nigricans. Journal of Clinical Endocrinology and Metabolism $199580614-618$.

38 Smith CP, Dunger DB, Williams AJ, Taylor AM, Perry LA, Gale EA et al. Relationship between insulin, insulin-like growth factor I and dehydroepiandrosterone sulfate concentrations during childhood, puberty and adult life. Journal of Clinical Endocrinology and Metabolism $198968932-937$.

39 Ibanez L, Potau N, Ong K, Dunger DB \& De Zegher F. Increased bone mineral density and serum leptin in non-obese girls with precocious pubarche: relation to low birthweight and hyperinsulinism. Hormone Research 200054 192-197.

40 Chapman IM, Wittert GA \& Norman RJ. Circulating leptin concentrations in polycystic ovary syndrome: relation to anthropometric and metabolic parameters. Clinical Endocrinology 1997 46 175-181.

41 Ankarberg C \& Norjavaara E. Diurnal rhythm of testosterone secretion before and throughout puberty in healthy girls: correlation with 17 beta-estradiol and dehydroepiandrosterone sulfate. Journal of Clinical Endocrinology and Metabolism $1999 \mathbf{8 4}$ 975-984.

42 Wabitsch M, Blum W, Muche R, Braun M, Huber F, Rascher W et al. Contribution of androgens to the gender difference in leptin production in obese children and adolescents. Journal of Clinical Investigation $1997 \mathbf{1 0 0} 808-813$.

43 Apter D, Butzow T, Laughlin GA \& Yen SS. Accelerated 24-hour luteinizing hormone pulsatile activity in adolescent girls with ovarian hyperandrogenism: relevance to the developmental phase of polycystic ovarian syndrome. Journal of Clinical Endocrinology and Metabolism 199479 119-125.

44 Ibanez L, Potau N, Virdis R, Zampolli M, Terzi C, Gussinye M et al. Postpubertal outcome in girls diagnosed with premature pubarche during childhood: increased frequency of functional ovarian hyperandrogenism. Journal of Clinical Endocrinology and Metabolism 199376 1599-1603.

Received 27 March 2001

Accepted 11 January 2002 